\title{
Research on Drilling and Sealing Technology for Cross Bedding of Superthick Coal Seam
}

\author{
Yao-bin Li $\mathbb{D},{ }^{1}$ Cai-Hao Yue $\mathbb{D}^{2},{ }^{2}$ and Xin Guo $\mathbb{D}^{2}$ \\ ${ }^{1}$ Joint National-Local Engineering Research Center for Safe and Precise Coal Mining, \\ AnHui University of Science and Technology, Huainan 232002, Anhui, China \\ ${ }^{2}$ School of Safety Science and Engineering, Anhui University of Science and Technology, Huainan 232001, Anhui, China \\ Correspondence should be addressed to Cai-Hao Yue; w17638134864@163.com
}

Received 20 November 2021; Accepted 4 January 2022; Published 1 February 2022

Academic Editor: Wei-yao Guo

Copyright (C) 2022 Yao-bin Li et al. This is an open access article distributed under the Creative Commons Attribution License, which permits unrestricted use, distribution, and reproduction in any medium, provided the original work is properly cited.

Gas disasters have been affecting coal mine safety production. With the gradual deepening of coal resources development, whether gas extraction meets the standard is particularly important. In view of the low extraction efficiency, through theoretical and numerical simulation combined with field measurement, the upper and lower cross bedding drilling is studied. Through the simulation and comparison of gas pressure at different extraction time and the gas pressure changes when the spacing of boreholes is $8 \mathrm{~m}, 10 \mathrm{~m}$, and $12 \mathrm{~m}$, the results show that, under the designed parameters, when the pressure value at the middle of the two boreholes starts to be less than $0.74 \mathrm{Mpa}$, the standard extraction time of the upper and lower cross strata boreholes is 160 days, and the most suitable spacing of boreholes is $10 \mathrm{~m}$. Combined with the actual situation of Baode Mine, the extraction effect of cross drilling and parallel drilling was compared. The research shows that the predrainage effect of cross drilling is obviously better than that of parallel drilling. Cross drilling improves the predrainage effect, prolongs the action time of gas extraction by drilling, and effectively eliminates the risk of coal seam outburst.

\section{Introduction}

China has been developing sustainable energy, pursuing energy transformation, and has been reducing the proportion of coal. Although the proportion of coal is declining, it is undeniable that China's national conditions are dominated by coal, and coal resources [1] are particularly important for China's energy security and stability. The geological structure of coal seam in China is complicated, the gas permeability is poor, and the gas disaster is increasingly serious. After decades of development, coal mine gas extraction technology [2-4] has become an important means of controlling coal seam gas.

Many scholars at home and abroad have conducted research on cross drilling, and many of them have analyzed the pumping effect of cross-drilling and compared it with that of other drilling methods. Through the theoretical analysis and experimental study of cross drilling, Wang et al. [5] show that cross drilling can increase the amount of gas pumped from coal seam without increasing any engineering quantity, compared with the conventional way of hole layout. In view of the low and poor mining efficiency of coal seam, Yang [6] adopted the three-dimensional cross drilling technology to carry out field tests on 8401 working face in order to ensure daily safe and efficient production of coal mine. The gas drainage technology is compared with the traditional drilling arrangement methods such as horizontal cross hole and parallel hole. The results show that the drainage effect is better than that of plane intersecting holes and parallel holes arrangement, which effectively reduces the occurrence of coal mine accidents and opens up a new technical way. In order to solve the present situation that the gas extraction effect of coal seam is not ideal, Wang [7] applied three-dimensional cross drilling technology to study gas drainage effect of bedding and compared it with other traditional gas extraction technologies and analysis, and the results confirmed that the three-dimensional cross drainage gas drilling technology does have its advantages, better 
extraction effect. For the problems existing in high gas and low permeability coal seam, Zhang et al. [8] and Liu et al. [9] carried out the experimental application of cross drilling predrainage coal seam gas technology in the working face. Compared with the traditional parallel drilling, the predrainage rate was improved. Similarly, in order to solve the problems of poor permeability and poor gas extraction effect of coal seam in working face. Ren [10] adopted gas extraction technology of oblique cross drilling, which was compared with parallel drilling and proved the practicality of gas extraction of oblique cross drilling. Chen et al. [11] in the No. 10 Mine of Pingmei Group, conducted a predrainage test of gas in the coal seam by cross holes and found that the natural gas emission effect of cross holes was better than that of parallel holes, and the limit drainage amount was 1.2 times that of parallel holes. With the continuation of drainage time, the drainage rate of cross holes was higher than that of parallel holes.

Some scholars have studied cross drilling and obtained some extraction parameters of drilling. Zhu and Xiang [12] combined with the conditions of a coal seam in Shanxi, compared the extraction effects of different aperture sizes and different spacing in the cross hole layout, and finally analyzed the optimal extraction parameters of boreholes. $\mathrm{Wu}$ and $\mathrm{Wu}$ [13] investigated the gas effect of predrainage of cross-drilling along bedding in No. 3 coal seam, conducted data analysis, and determined the most appropriate spacing and time of predrainage drilling. Shang et al. [14] introduced the experiment working surface profile and the layout of drainage boreholes and analyzed the relationship between the natural gas emission of the cross boreholes and time, the change of the gas extraction capacity of the boreholes in the experimental area with time, and the relationship between the drainage rate and time under different cross hole densities. Finally, the reasonable drilling hole spacing for coal seam crossing was determined. Zhao and Yue [15] studied gas drainage of cross drilling in a certain coal seam and applied software to calculate the reasonable vertical distance of cross drilling.

In terms of numerical simulation, according to the solidflow coupling theory, Wang et al. [16] conducted numerical simulation of gas drainage from parallel boreholes and cross boreholes by using finite element algorithm and Microsoft Visual Basic6.0 programming. It is calculated that the gas drainage volume of cross drilling is about $46 \%$ higher than that of parallel drilling, which has been proved in practice.

There are many coal mines in China with a large amount of gas extraction, but the overall extraction rate of coal mines is low, mainly due to the difficulty of extraction or the lack of attention to gas extraction. Most scholars have also made contributions to the cross-drilling of coal seams, but few scholars have studied the cross-drilling of gas extraction in ultrathick coal seams.

In order to solve the problem of low gas extraction rate in Baode mine, it also provides technical support for gas treatment in other thick and superthick coal seams. We adopt the way of combining theoretical simulation and field test, based on the data collected in the field, and combined with the gas extraction model of cross bedding borehole, the variation law of gas pressure under different extraction time and different spacing of boreholes was analyzed. 160 days was obtained as the standard extraction time under the current design parameters, and the spacing of boreholes was $10 \mathrm{~m}$. Finally, according to the actual situation of Baode Mine, the data were analyzed, and the extraction parameters of cross drilling were obtained, which were compared with parallel drilling.

\section{The Situation of No. 8 Coal Seam in Baode Coal Mine}

Underground mining coal seam thickness classification is generally divided into: thin coal seam, medium thick coal seam, thick coal seam, and extrathick coal seam. The coal seam thickness less than or equal to 1.3 meters is thin coal seam. The thickness of $1.3 \mathrm{~m}$ to $3.5 \mathrm{~m}$ is medium thick coal seam. Thick coal seams with a thickness greater than 3.5 meters. When the thickness of the coal seam is greater than 8 meters, it is extremely thick. Baode coal mine, according to the result of approval of gas grade appraisal of mine over the years, the mine is high gas mine. No. 8 coal seam is the first level, and the service life is 23.2a. The average thickness of the coal seam is $7.36 \mathrm{~m}$, dip angle is $3-9^{\circ}$, geological structure is simple, coal dust has explosion risk, belongs to the II class spontaneous combustion coal seam. The coal seam is located above S3 sandstone at the bottom of Shanxi Formation (P1 S). The coal thickness is $2.15-10.50 \mathrm{~m}$, with an average of $7.36 \mathrm{~m}$. The thickness of pure coal is $3.19-8.84 \mathrm{~m}$ with an average of $6.01 \mathrm{~m}$. Medium to extrathick coal seam is mainly thick coal seam. The structure of coal seam is complicated, including 0-8 layers of gangue, usually 3-4 layers. The total thickness of gangue is $0.3-2.6 \mathrm{~m}$, with an average thickness of $1.06 \mathrm{~m}$. The roof is sandy mudstone or mudstone, partially coarse-grained sandstone, and the bottom plate is mainly mudstone, secondary siltstone. There are 58 coal spots in the whole area, and the thickness of coal seam is recoverable. The mining index of coal seam is 1 , and the coefficient of variation is $33 \%$, which is a stable and recoverable coal seam in the whole area. The thickness of the coal seam is generally thick in the west and thin in the east and thick in the middle and thin on both sides. The old coal seam is mostly coarse, medium, and fine-grained sandstone with a thickness of $5-20 \mathrm{~m}$ and an average of $12.67 \mathrm{~m}$. The direct roof is developed in most sections, and the lithology is sandy mudstone, siltstone, mudstone, and thin layer sandstone with a thickness of $0-16.13 \mathrm{~m}$. It is mudstone and carbonaceous mudstone with thickness less than $0.5 \mathrm{~m}$.

\section{Mechanism of Increasing Gas Extraction by Cross Drilling}

In order to study the stress distribution around the borehole of coal seam extraction, the elastoplastic stress theory of roadway surrounding rock is introduced. There is a circular drilling hole with a radius of $R_{0}$, and the surrounding rock of the drilling hole is composed of three parts: plastic zone, elastic zone, and original rock zone. It is assumed that the stress of the original rock is isotropic $\left(P_{0}\right)$, the lateral 
pressure coefficient $\lambda=1$, the surrounding rock is homogeneous, isotropic, and creep free, the plastic zone is the limit equilibrium zone, and the plastic zone radius is $R_{P}$. The borehole is located in deep buried rock, and the ratio of borehole depth to borehole diameter is large enough to be considered as plane strain problem. Any section of borehole is taken as its representative for mechanical analysis.

In polar coordinates, the plane strain of the elastic body satisfies the following equilibrium differential equation:

$$
\frac{d \sigma_{r}^{p}}{d r}+\frac{\sigma_{r}^{p}-\sigma_{\theta}^{p}}{r}=0
$$

In the formula, $r$ is the distance from any point in the plane to the center of the borehole, $\mathrm{m}$.

The rock mass in the plastic zone satisfies not only the equilibrium equation but also the linear Mohr-Coulomb failure strength criterion:

$$
\sigma_{\theta}^{p}=\xi \sigma_{r}^{p}+\sigma_{c} .
$$

Substitute (2) into (1) and obtain

$$
\frac{d \sigma_{r}^{p}}{d r}+\frac{(1-\xi)}{r} \sigma_{r}^{p}=\frac{\sigma_{c}}{r} .
$$

From the general solution of the inhomogeneous linear equation, we have

$$
\sigma_{r}^{p}=e^{-\int 1-\xi / r d r}\left(\int \frac{\sigma_{c}}{r} e^{-\int 1-\xi / r d r} d r+C\right) .
$$

Combined with stress boundary condition $\left.\sigma_{r}^{p}\right|_{r=R_{0}}=0$, we can solve

$$
\left\{\begin{array}{l}
\sigma_{r}^{p}=\frac{\sigma_{c}}{\xi-1}\left[\left(\frac{R}{R_{0}}\right)^{\xi-1}-1\right] \\
\sigma_{\theta}^{p}=\frac{\sigma_{c}}{\xi-1}\left[\xi\left(\frac{R}{R_{0}}\right)^{\xi-1}-1\right] .
\end{array}\right.
$$

The stress component in the elastic zone of surrounding rock is

$$
\left(\begin{array}{c}
\sigma_{r}^{e}=P_{o}\left(1-\frac{R^{2}}{R_{0}^{2}}\right)+\sigma_{R_{p}} \frac{R^{2}}{R_{0}^{2}}, \\
\sigma_{\theta}^{e}=P_{o}\left(1+\frac{R^{2}}{R_{0}^{2}}\right)-\sigma_{R_{p}} \frac{R^{2}}{R_{0}^{2}} .
\end{array}\right) .
$$

Here, $\sigma_{r}^{p} 、 \sigma_{r}^{e}$ is the radial stress of rock mass in plastic zone and elastic zone, respectively; $\sigma_{\theta}^{p}, \sigma_{\theta}^{e}$ is the circumferential (tangential) stress of rock mass in plastic zone and elastic zone, respectively; $R$ is the radius of borehole $\left(R \geq R_{0}\right) ; \sigma_{\mathrm{c}}$ is the uniaxial compressive strength limit of the surrounding rock; $\sigma_{c}=2 c \cos \phi / 1-\sin \phi ; \sigma_{R_{p}}$ is the radial stress at interface $\mathrm{R}_{\mathrm{p}}$ of the elastic-plastic region; $\xi$ is the plastic coefficient, $\xi=1+\sin \phi / 1-\sin \phi ; \phi$ is the internal friction angle of rock mass; and $C$ is the cohesion of rock mass.
At the interface between the elastic zone and plastic zone, there are

$$
\left.\left(\sigma_{r}^{p}+\sigma_{\theta}^{p}\right)\right|_{r=R_{p}}=\left.\left(\sigma_{r}^{e}+\sigma_{\theta}^{e}\right)\right|_{r=R_{p}}=2 P_{0} .
$$

Substituting (5) into (7), the plastic zone radius $R_{P}$ is obtained as

$$
R_{P}=R_{0}\left[\frac{P_{0}(1-\sin \phi)-c(\cos \phi-\cot \phi)}{c \cot \phi}\right]^{1-\sin \phi / 2 \sin \phi} .
$$

It can be seen from (8) that, under certain conditions of coal seam itself, the radius of the plastic zone of borehole $R_{P}$ is proportional to the radius of borehole $R_{0}$. Within the radius of the plastic zone, surrounding rock is damaged and connected. Under the action of negative pressure of extraction, coal seam gas converges in the borehole and is pumped away.

According to the attenuation law of tangential stress distribution of surrounding rock of a single borehole, when the second borehole crosses above or below the first borehole, the concentrated stress coefficient of surrounding rock increases significantly under the influence of the concentrated stress of the first borehole, resulting in a larger plastic zone. At the same time, the plastic zone radius of the first borehole is increased by the stress of the second borehole. The range of mutual influence between the two boreholes is generally more than $5 \%$ of the original rock stress as the limit, and the influence radius $R_{i}=\sqrt{20} R_{0}$. If the distance between adjacent boreholes is greater than $2 R_{i}$, the two boreholes will not affect each other; otherwise, there is mutual influence. The significant result is that the plastic zone of both boreholes expands outwards. Cross drilling [17] can effectively improve the permeability of coal seam and increase the amount of gas predrainage, which makes use of the influence of plastic zone of surrounding rock of cross drilling on each other.

\section{Numerical Simulation}

Based on COMSOL Multiphysics software, the drilling extraction model of upper and lower cross bedding in Baode Mine was established, and relevant simulation analysis was carried out. The results are shown as follows.

4.1. Gas Extraction Mode. According to the parameters collected in the field, a gas drainage model of the upper and lower cross bedding borehole was established, as shown in Figure 1. The length and width of the model were $700 \mathrm{~m}$ and $260 \mathrm{~m}$, respectively. Basic parameters of coal mine: coal gas pressure is $2.5 \mathrm{Mpa}$, negative pressure of extraction is $13 \mathrm{KPa}$, and permeability is $3.85 \mathrm{MD}$. The group of drilling holes is constructed in the groove of the 81307 working face. Each group of 10 drilling holes has a length of $220 \mathrm{~m}$, a spacing of $10 \mathrm{~m}$, and a length of $8 \mathrm{~m}$. At the same time, part of the model is meshed as shown in Figure 2.

4.2. Gas Pressure Change under Different Extraction Time. The extraction time is an important parameter affecting the change of coal gas pressure. If the extraction time is too short, 


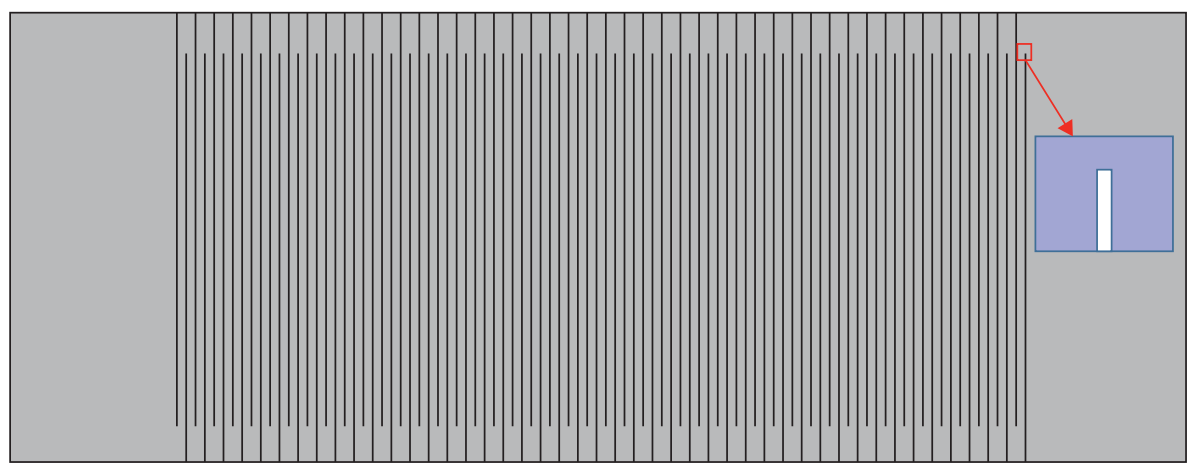

FIgURE 1: Gas drainage model of borehole across strata.

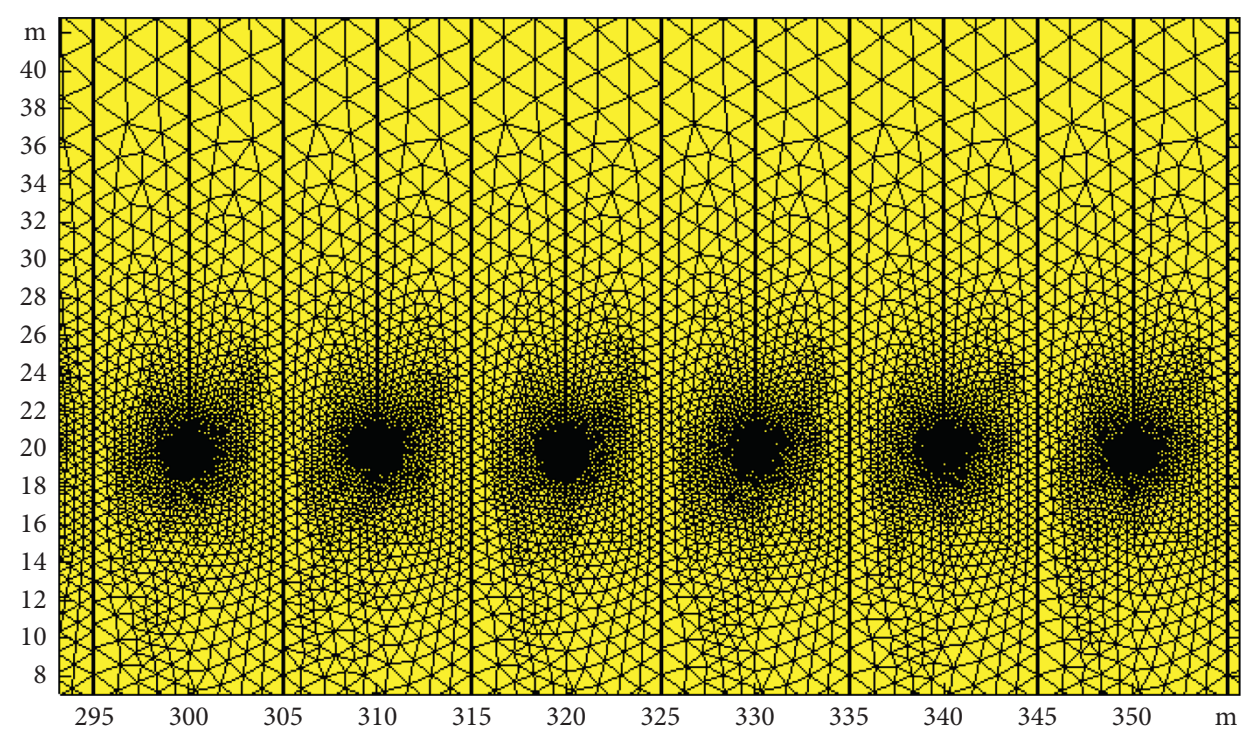

Figure 2: Meshing diagram.

the gas pressure will not decrease obviously and the extraction will not reach the standard. Extraction time is too long, will affect the mining speed, and is not conducive to the normal mining face. Figure 3 shows the change of gas pressure around the borehole under different extraction time. In order to observe the change of gas pressure more clearly, the gas monitoring line is set. The change of gas pressure on the monitoring line with extraction time is shown in Figure 4. Figure 5 shows the variation of gas pressure with time at a point in the middle of borehole group. In order to reflect the variation trend of gas pressure at different positions, another point at the edge of borehole group is compared with this point. The results are shown in Figures 6 and 7.

As can be seen from the figure, in the early stage of extraction, the influence range of drilling is small, and the gas pressure in most areas remains at a relatively high level. However, with the increase of extraction time, the influence range of drilling also expands, and the gas pressure decreases significantly. The simulation results show that the decrease of gas pressure in the early stage is larger than that in the late stage, and the drainage effect in the middle of the borehole is better than that at both ends. For the current drainage parameters, after 90 days of drainage, the gas pressure is less than $0.74 \mathrm{Mpa}$ within a range of $1 \mathrm{~m}$ around the borehole.
The spacing of each group of holes is $10 \mathrm{~m}$. Because it is a cross hole, there is still a range of $3 \mathrm{~m}$ between the two holes. After 180 days of extraction, the gas pressure in the coal body between the two boreholes falls below $0.74 \mathrm{MPa}$, reaching the target of outburst elimination. To be more precise, according to Figure 5, after about 160 days of pumping, the pressure value in the middle of the two holes begins to be less than $0.74 \mathrm{Mpa}$, so 160 days is the time of pumping up to standard under the current design parameters.

4.3. Gas Pressure Changes under Different Spacing of Boreholes. The spacing between each group of boreholes in Baode Mine is $10 \mathrm{~m}$. Since the actual distance between each two boreholes is $5 \mathrm{~m}$, according to the analysis in Section 4.2, at this spacing, it takes about 160 days to basically achieve the standard of extraction. In order to ensure the production succession of Baode Mine, the extraction conditions of $8 \mathrm{~m}$ and $12 \mathrm{~m}$ hole spacing are analyzed, respectively, as shown in Figures 8 and 9 . When the spacing is $8 \mathrm{~m}$, the gas pressure in the middle part of the two boreholes drops the fastest, and the extraction time reaches the standard is about 100 days. When the spacing is $10 \mathrm{~m}$, the standard time is 160 days. When the spacing between holes is $12 \mathrm{~m}$, at least 230 days of 

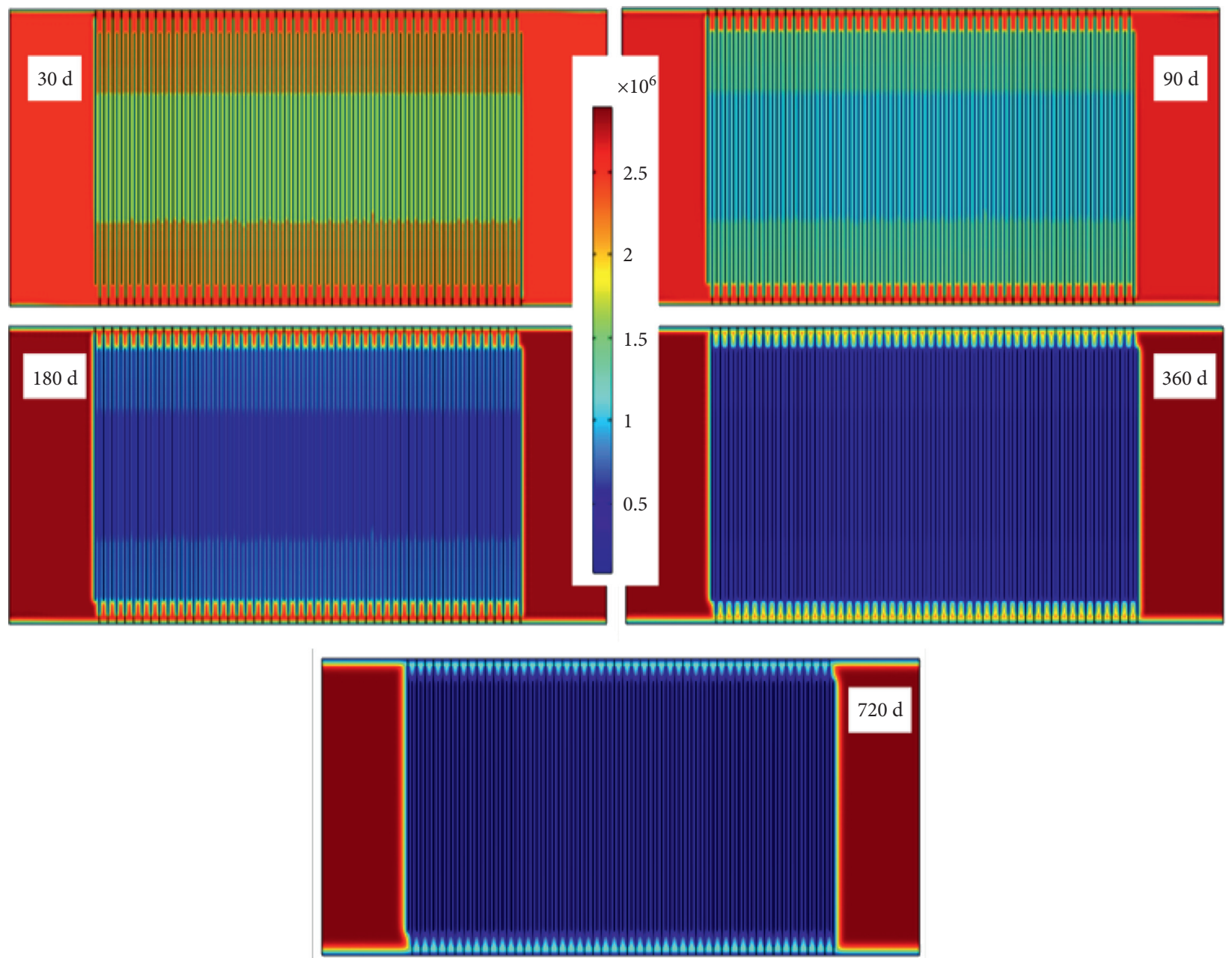

Figure 3: Gas pressure under different extraction time.

pumping is needed to achieve the purpose of outburst elimination. It can be clearly seen from Figure 8 that, after 100 days of drainage, the gas pressure between the two holes with a distance of $8 \mathrm{~m}$ is less than or equal to $0.74 \mathrm{Mpa}$, while there are a large number of areas with high gas pressure between the two holes with a distance of $10 \mathrm{~m}$ and $12 \mathrm{~m}$, especially in the middle of the two holes, which requires longer drainage to achieve the purpose of outburst suppression. Only after 230 days of pumping did drilling with spacing of $12 \mathrm{~m}$ begin to reach the standard of pumping. According to the figure analysis, after 230 days of pumping, all the holes with three spacing achieved pumping standards. However, a small hole spacing will increase the number of holes and increase the construction cost, while a large hole spacing will affect the mining activities, so the selection of hole spacing should take into consideration the production cost of Baode Mine and the allowable time of extraction to reach the standard.

\section{Analysis of Cross Drilling Pumping Effect}

The current mine drainage rate of Baode Coal mine is $49 \%$, the predrainage rate is $20-30 \%$, the concentration of coal seam predrainage gas is $20-30 \%$, predrainage rate and predrainage gas concentration are low, predrainage coal seam gas is very important for high gas mine, and the coal seam gas should be extracted as much as possible in advance. In the following part, the pumping effect of cross drilling and parallel drilling is compared to illustrate the advantages of cross drilling.

5.1. Drill Hole Layout. The cross drilling is located in the 81308 glue transport channel in the third panel of Baode Coal Mine. The spacing of the cross drilling is $5 \mathrm{~m}$, and 16 drillings are constructed. The drilling hole is at a high level, the opening height is $1.5 \mathrm{~m}$, and the working face is $60^{\circ}$. The length of the oblique drilling is $230 \mathrm{~m}$, the length of the drilling is $200 \mathrm{~m}$, and the diameter of the drilling is $113 \mathrm{~mm}$ drilling, layout as shown in Figure 10. Parallel arrangement of drilling spacing $5 \mathrm{~m}$, construction of 8 boreholes, drilling hole height of $1.5 \mathrm{~m}$, with the working surface into $60 \mathrm{de}-$ grees, opening position from the bottom plate $1.3 \mathrm{~m}$, extraction drilling length of about $200 \mathrm{~m}$, drilling diameter of $113 \mathrm{~mm}$, and drilling arrangement is shown in Figure 10.

5.2. Comparison of Extraction Effect. As shown in Figure 11, the extraction concentration of boreholes in the cross-drilling mode is $62.4-90.2 \%$, and the average 


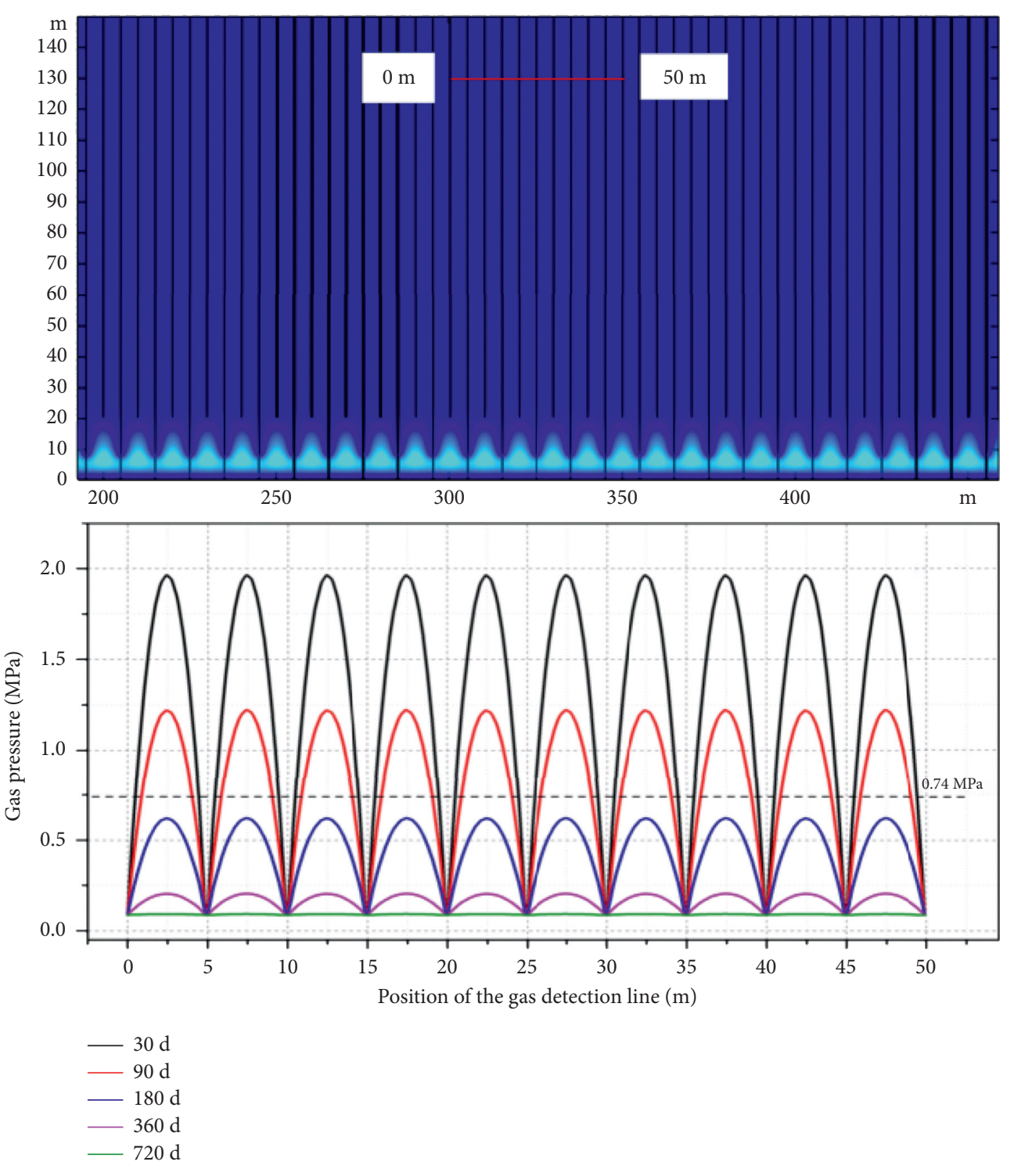

Figure 4: Gas pressure changes at different extraction times.

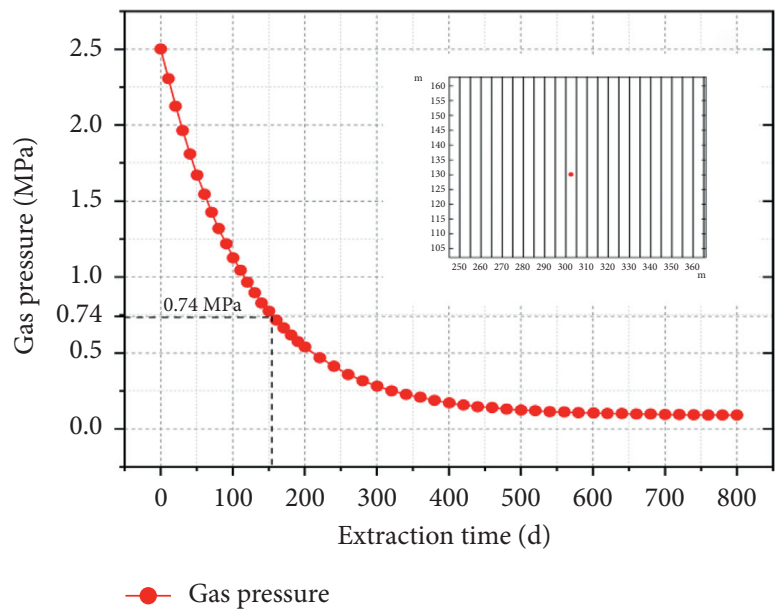

FIGURE 5: Gas pressure change over time at the monitoring point. 


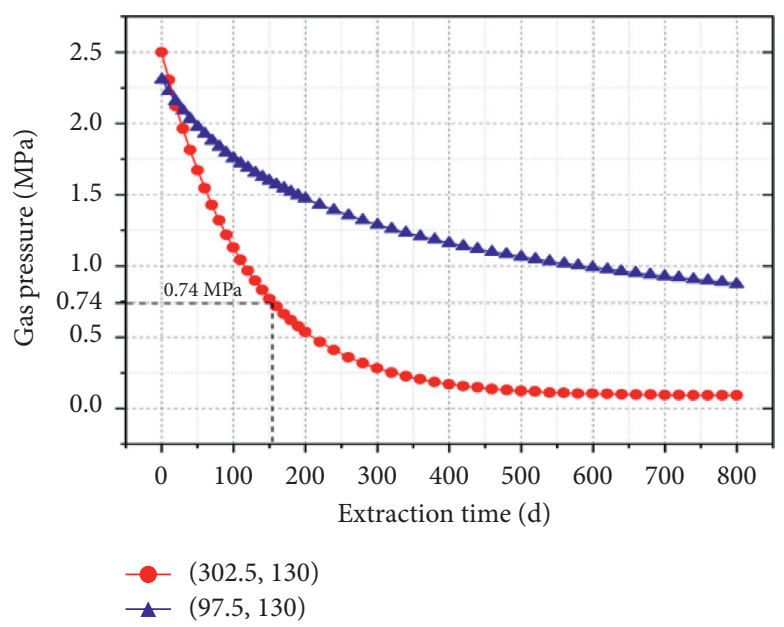

FIGURE 6: Gas pressure changes with time at different monitoring points.

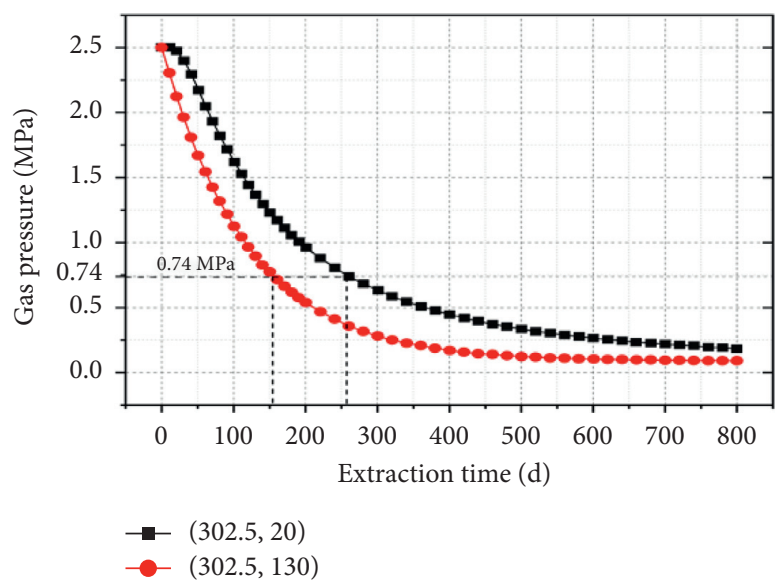

FIGURE 7: Gas pressure changes with time at different monitoring points.

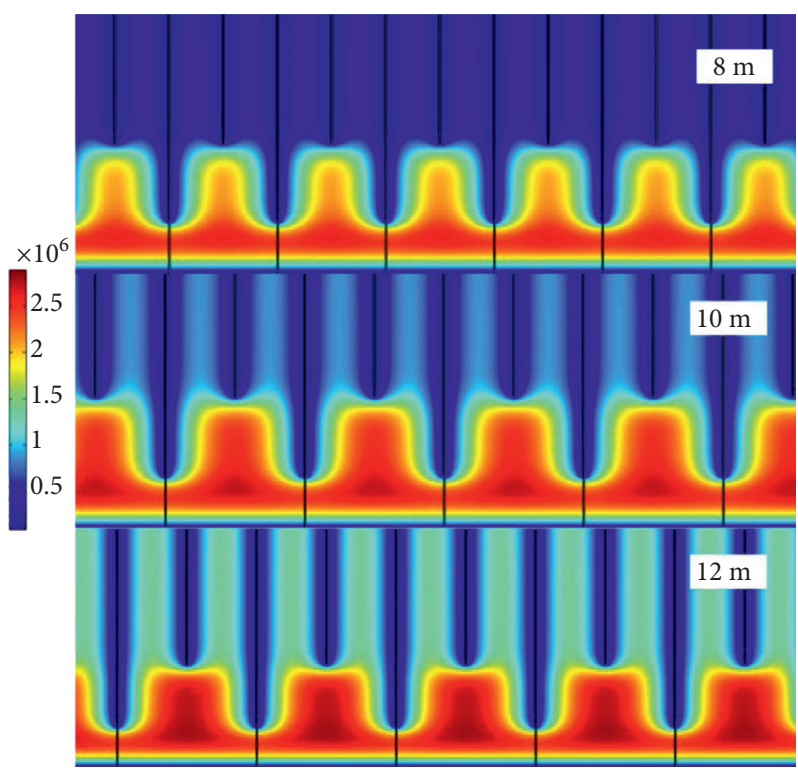

FIGURE 8: Gas pressure distribution at different spacing of boreholes. 


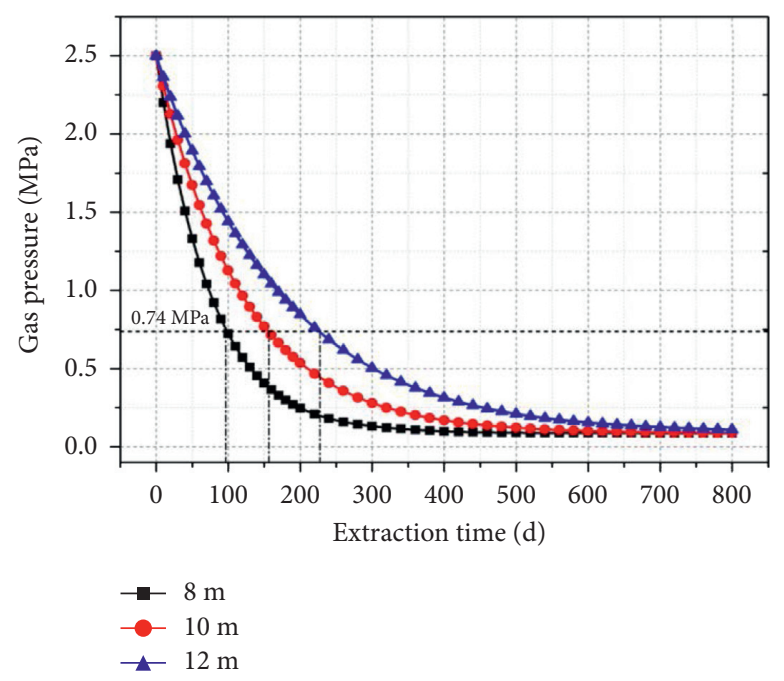

FIgURE 9: Variation of gas pressure at different spacing of boreholes.

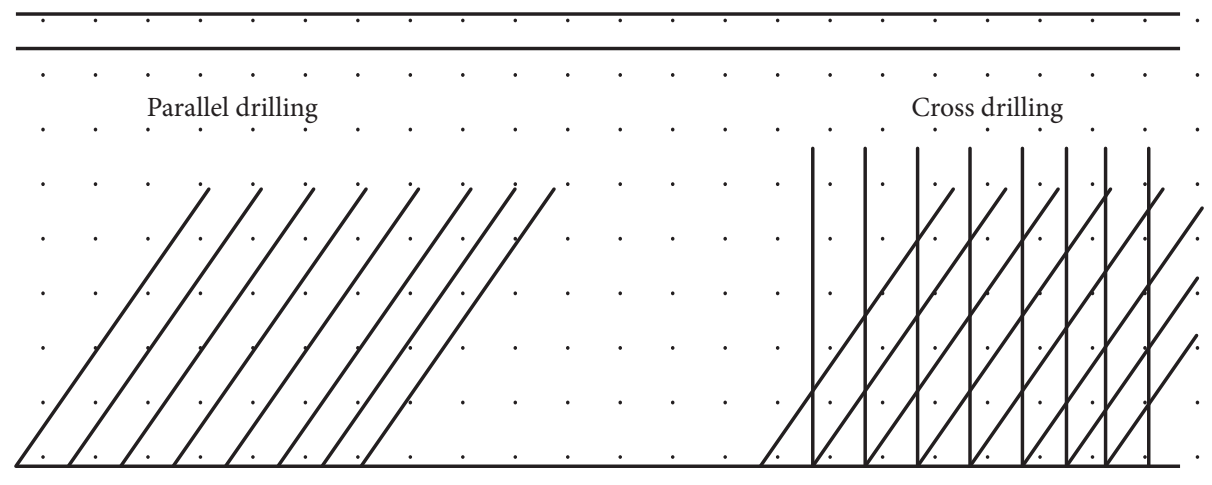

Figure 10: Drill hole layout.

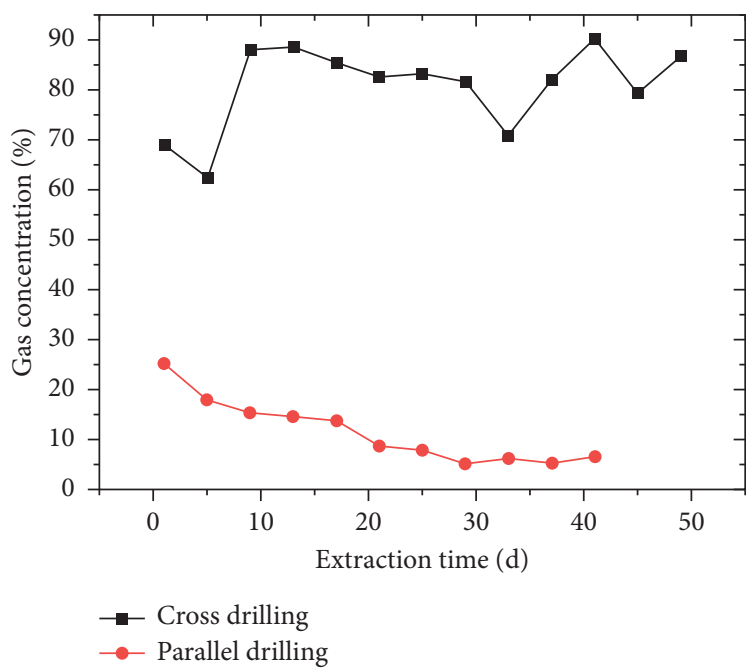

FIgURE 11: Change of drilling extraction concentration.

extraction concentration of boreholes is $81 \%$. In parallel drilling, the extraction concentration is $5.2 \%-25.2 \%$, and the average extraction concentration is $12 \%$.
As shown in Figure 12, the pure amount of gas extracted from boreholes in the cross-drilling mode is $0.11-0.45 \mathrm{~m}^{3} /$ min, and the average pure amount of gas extracted from 


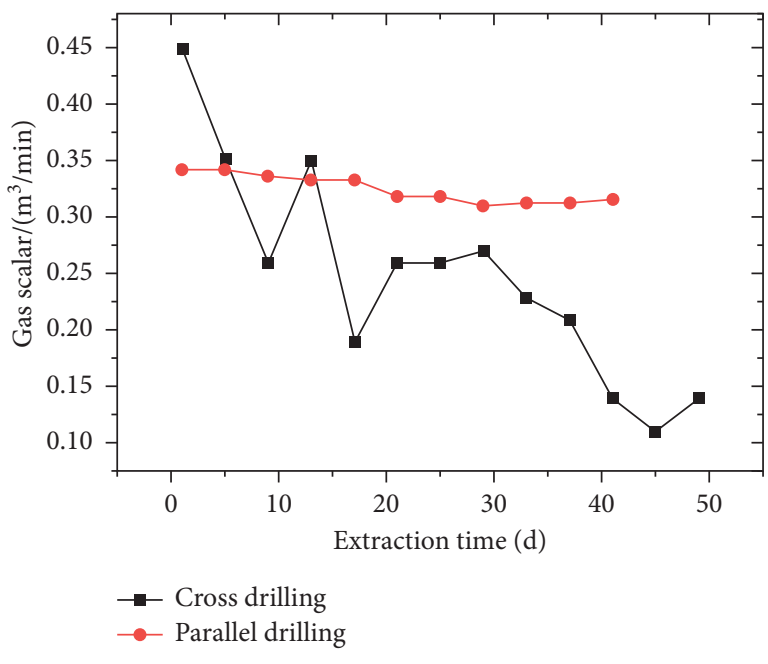

FIgURE 12: The change of gas scalar.

boreholes is $0.25 \mathrm{~m}^{3} / \mathrm{min}$. The gas purity of parallel drilling is $0.312-0.342 \mathrm{~m}^{3} / \mathrm{min}$, and the average gas purity of drilling is $0.33 \mathrm{~m}^{3} / \mathrm{min}$.

5.3. Results Analysis. From the above data processing, it can be seen that, in the cross drilling area, the average gas extraction concentration is $81 \%$. After 45 days of pre-extraction, the gas concentration measured in the borehole is $87.2 \%$. The gas concentration in the borehole is always maintained at a high value, and the gas extraction rate is $38.68 \%$. In the parallel drilling area along the layer, the average gas extraction concentration of the borehole is $12 \%$, and the residual gas content of the working face is $9.2 \%$ after 45 days of pre-extraction. The gas concentration of the borehole shows a trend of obvious decrease. The result shows that the prepumping effect of cross drilling is better than that of parallel drilling.

\section{Conclusions}

(1) According to the parameters collected on-site, the drilling extraction model of the upper and lower cross layers of Baode Mine was established by using COMSOL Multiphysics software, and the change of gas pressure under different extraction times was simulated. After about 160 days of extraction, the pressure value in the middle of the two boreholes began to be less than $0.74 \mathrm{Mpa}$. The time of drilling and extraction up and down cross bedding is 160 days.

(2) According to the established drainage model, the gas pressure changes at different hole spacing were simulated, and the gas pressure changes at $8 \mathrm{~m}, 10 \mathrm{~m}$, and $12 \mathrm{~m}$ hole spacing were compared. When the spacing is $8 \mathrm{~m}$, the standard pumping time is about 100 days; when the spacing is $10 \mathrm{~m}$, the standard pumping time is 160 days; when the spacing is $12 \mathrm{~m}$, the minimum pumping time is 230 days to achieve the purpose of outburst elimination. Considering the production cost of Baode Mine and the allowable extraction time to reach the standard, the spacing of boreholes is determined to be $10 \mathrm{~m}$.

(3) The average concentration of gas extracted from the cross drilling area is $81 \%$, and that from the parallel drilling area is $12 \%$.After 45 days of predrainage, the gas concentration in the cross drilling area is $87.2 \%$, while the residual gas content in the working face after 45 days of predrainage in the parallel drilling is $9.2 \%$. The result shows that the prepumping effect of cross drilling is better than that of parallel drilling.

\section{Data Availability}

Data can be obtained from the corresponding author upon request.

\section{Conflicts of Interest}

The authors declare no potential conflicts of interest with respect to the research, authorship, and/or publication of this article.

\section{Acknowledgments}

The project was supported by the Open Research Grant of Joint National-Local Engineering Research Center for Safe and Precise Coal Mining (Grant no. EC2021012), China Coal Energy Research Institute Co., Ltd. (contract no.: ZMYHT*AJ-W-WSZNCC-02-21-090), the National Natural Science Foundation of China (nos. 51934007 and 51904013), and Shandong Key S\&T Innovation Engineering Project (no. 2019JZZY020504).

\section{References}

[1] K. Li, "Current situation and countermeasures of clean and efficient utilization of coal resources in China," Inner Mongolia Coal Economy, vol. 15, pp. 175-176, 2020.

[2] M. Huang, "Research and application of gas extraction technology in coal mine," Energy and Energy Conservation, vol. 9, pp. 54-55+58, 2021.

[3] Y. P. Cheng, J. H. Fu, and Q. X. Yu, "Development of coal mine gas extraction technology in China," Journal of Mining and Safety Engineering, vol. 26, no. 2, pp. 127-139, 2009.

[4] K. J. Wang and X. H. Zhang, "Development status and prospect of gas extraction technology in China coal mine," China coalbed methane, vol. 1, pp. 13-16+39, 2006.

[5] K. J. Wang, Y. A. Wang, Z. Z. Xu, and J. G. Wang, "Cross drilling pre-drainage of coal seam gas," Coal mine safety, no. S1, pp. 78-81, 2006.

[6] L. P. Yang, "Research and application of pre-draining coal seam gas technology with three-dimensional cross drilling," Earth and Environmental Science, vol. 514, no. 9, p. 022052, 2020.

[7] Y. F. Wang, "Research on gas drainage technology of low permeability coal seam based on three-dimensional cross drilling," Coal Mine Machinery, vol. 39, no. 2, pp. 29-30, 2018.

[8] W. Y. Zhang, J. G. Zheng, H. P. Zhao, G. Q. You, and C. Jin, "The technical practice of cross borehole pre-drainage gas in 13105 working face of a mine," Coal Technology, vol. 35, no. 10, pp. 199-201, 2016. 
[9] Q. Liu, L. F. Wang, and Q. Q. Cao, "Experimental study on cross-hole pre-drainage technology in high gas and low permeability coal seam," World Science and Technology Research and Development, vol. 38, no. 2, pp. 371-376, 2016.

[10] Z. J. Ren, "Research and application of this coal seam oblique cross drilling gas extraction technology," Energy Technology and Management, vol. 41, no. 1, pp. 39-40, 2016.

[11] G. X. Chen, Y. W. Wang, and B. Sun, "Application of cross drilling pre drainage of coal seam gas in Pingdingshan Mining Area," Coal Mine Safety, vol. 10, pp. 1-3, 2002.

[12] X. H. Zhu and Z. C. Xiang, "Research on the rational extraction technology of the coal seam based on cross-drilling arrangement," Energy Technology and Management, vol. 42, no. 5, pp. 21-23, 2017.

[13] Q. J. Wu and Q. Wu, "Study on the effect of pre-drainage of no. 3 coal seam gas by cross drilling in Yongan Coal Mine," Inner Mongolia Coal Economy, vol. 9, pp. 139-140, 2015.

[14] Q. Shang, Z. W. Yang, and J. W. Jin, "Study on reasonable hole spacing of cross drilling for pre drainage coal seam gas," Coal Science and Technology, vol. 37, no. 9, pp. 48-50, 2009.

[15] X. J. Zhao and F. T. Yue, "Determination of vertical distance of gas drainage by cross drilling," Journal of Liaoning Technical University, vol. 1, pp. 5-7, 2000.

[16] Y. G. Wang, J. R. Wang, and J. G. Yang, "Numerical simulation analysis of gas drainage by cross drilling," Coal Mine Mining, vol. 4, pp. 65-67, 2000.

[17] Q. Liu, L. F. Wang, and Q. Q. Cao, "Experimental study on cross drilling gas pre-drainage technology in coal seam with high gas and low permeability," World science and Technology research and development, vol. 38, no. 2, pp. 371-376, 2006. 